\title{
Original Article \\ Prognostic Importance of Acute Heart Failure Persistence in Patients with ST-elevation Myocardial Infarction
}

\author{
Sergey Kozhukhov ${ }^{1 *}$, Alexander Parkhomenko ${ }^{2}$, Nataliia Dovganych ${ }^{1}$ \\ ${ }^{1}$ Department of Clinical Pharmacology, National Scientific Center, The M.D. Strazhesko Institute of \\ Cardiology, Kiev, Ukraine, ${ }^{2}$ Department of Emergency Cardiology, National Scientific Center, The M.D. \\ Strazhesko Institute of Cardiology, Kiev, Ukraine. \\ Address for correspondence: Sergey Kozhukhov, Department of Clinical Pharmacology, National \\ Scientific Center, The M.D. Strazhesko Institute of Cardiology, Kiev, Ukraine. E-mail: s.kozhukhov@i.ua
}

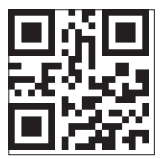

Quick Access Code

How to cite this article: Kozhukhov S, Parkhomenko A, Dovganych N. Prognostic Importance of Acute Heart Failure Persistence in Patients with STelevation Myocardial Infarction. Journal of Medical Research and Innovation. 2018;2(1): e000100

Doi: 10.15419/jmri.100

Publication history: Received: 08/11/2017 Accepted: 01/01/2018 Published: 02/01/2018

Editors: Dr. Varshil Mehta and Dr. Nikhil Nalluri

Copyright: Kozhukhov S. This is an open access article distributed under the terms of the Creative Commons Attribution License CC-BY 4.0., which permits unrestricted use, distribution, and reproduction in any medium, provided the original author and source are credited.

Funding: NIL Conflict of Interest: NIL

\begin{abstract}
Introduction: Acute heart failure (AHF) is one of the most frequent complication of acute myocardial infarction (AMI). It is not only associated with a several-fold increase of in-hospital mortality but also, worsens the long-term survival in comparison to those without AHF. The AHF is observed to be more in AMI patients whose in-hospital stay is more than 3 days. The clinical implications and prognostic accuracy of the AHF term in the setting of AMI are yet unknown. Methods: We observed 1,104 consecutive cardiac care patients, who were admitted with ST-elevation AMI (STEMI). They were divided into groups according to the AHF presence $\{\mathrm{AHF}(+) n=334$ and $\mathrm{AHF}(-) n=764\}$. Among $334 \mathrm{AHF}(+)$ patients: 252 patients were found to have a transient $\mathrm{AHFt}(+)$, whereas 82 of $\mathrm{AHF}(+)$ patients had persistent $\mathrm{AHFp}(+)$ during inhospital period. Patients' baseline characteristics, blood analysis, left ventricle (LV) and renal function data were assessed and analyzed on the admission day and 10th day post-admission. The follow-up was conducted on the 30th day and after 2 years. Results: STEMI patients accompanied by AHF(+) were older, presented mostly with anterior AMI $(p<0.01)$, had lower LV ejection fraction (EF) $(p<0.01)$ and a higher heart rate $(p<0.05)$. Their rates of comorbidities and of in-hospital complications such as recurrent angina, reinfarction, $\mathrm{LV}$ aneurism were higher in comparision to $\mathrm{AHF}(-)$ patients. $\mathrm{AHFp}(+)$ patients had the shortest time from symptoms onset before thrombolysis in comparision to AHFt(+) and AHF(-) groups. Partial recovery of cardiac function according to Left ventricular ejection fraction (LVEF) and end-systolic volume index, occurred mainly in $\mathrm{AHF}(-)$ and $\mathrm{AHFt}(+)$ patients on the 10th day post-admission, but not in $\mathrm{AHFp}(+)$. STEMI patients with $\mathrm{AHFp}(+)$ demonstrated a larger infarct size, higher C-reactive protein and VGEF level, fasting glucose and heart rate on admission, higher erythrocyte sedimentation rate, absence of heart rate normalization on the 10th day post-admission. All of these markers were the signs of severe myocardial damage and inflammation, which can reflect worse recovery in AHF patients despite optimal management. Patients with $\mathrm{AHF}(+)$ had renal dysfunction on admission while its creatinine clearance $(\mathrm{CrCl})$ decreased during the in-hospital period which is the reflection of a poor prognosis. Cardiovascular mortality and nonfatal $\mathrm{Ml}$ were significantly higher in the $\mathrm{AHFp}(+)$ group as compared to the $\mathrm{AHFt}(+)$ and the $\mathrm{AHF}(-)$ groups during the 30 days and 2 years of follow-up. Conclusion: The AHF is a frequent STEMI complication. AHF lasting $>3$ days had worse short- and long-term prognosis. Therefore, an aggressive strategy should be recommended particularly in patients who have clinical signs and symptoms of persistent AHF.
\end{abstract}

Keywords: Myocardial infarction, Acute heart failure, Infarct size, Survival.

\section{Introduction}

Over the last few decades, a significant progress has been achieved in the treatment of patients with acute myocardial infarction (AMI), primarily due to the use of pharmacological or mechanical reperfusion strategies; second, due to medical therapy optimization. ${ }^{[1,2]}$ Advances in the treatment have led to survival rate improvement in AMI patients as a result of an infarct-related artery opening that minimize the size of the myocardial damage. As the results show, despite 
of progress in management more than one third the AMI patients have complication - acute heart failure (AHF). It is clear that natural history of patients with coexisting AMI and AHF leads to poor survival. ${ }^{[3]}$

Heart cell damage is the main factor of AHF occurrence, caused by ischemia/reperfusion injury, which often leads to deterioration or even loss of heart function, limits the benefits of reperfusion after AMI and has negative impact on global outcome. ${ }^{[4,5]}$

Large number of predictive models and risk scores exist to stratify the management of AHF patients. However, there are only few studies which have assessed the utility of AHF duration in ST-elevation myocardial infarction (STEMI) patients. ${ }^{[6]}$ The clinical implications and prognostic accuracy of AHF terms in the setting of AMI yet unknown.

Therefore, we aimed to assess the prevalence and prognostic implications of transient versus persistent AHF among patients hospitalized with acute STEMI and to evaluate the short- and long-term outcomes in patients treated according to contemporary recommendations.

\section{Methods}

\section{Study population}

Patients were admitted to the Emergency Cardiology Department of the National Scientific Center "The M.D. Strazhesko Institute of Cardiology," Kiev, Ukraine.

Patients have been enrolled in our study according to the following criteria of inclusion:

- $\quad$ Age $\geq 21$ years;

- Admission to the hospital due to STEMI. Diagnosis of AMI was based on serum markers level more than twice the upper limit of normal for $\mathrm{MB}$ fraction of creatine kinase and chest pain lasting for at least 20 mins and electrocardiogram (ECG) changes on at least 2 contiguous leads with significant ST-elevation;

- $\quad<24 \mathrm{~h}$ from symptoms onset of AMI;

- Written informed consent to participate in the study.

The exclusion criteria were as follows:

- $\quad$ Cardiogenic shock (Killip IV);

- $\quad$ Hepatic insufficiency (AST, ALT >3 times the ULN);

- Severe renal insufficiency (serum creatinine $\geq 200 \mu \mathrm{mol} / \mathrm{I}$ );

- Coagulopathy;

- Active cancer.

The study was conducted in accordance with the Declaration of Helsinki and was approved by the local ethics committee.

\section{Study protocol}

Each patient underwent a physical examination with measuring of blood pressure, heart rate, body mass index, and followed by standard diagnostic tests (ECG, biomarkers). Furthermore, we analyzed complications during in-hospital period, infarct size and laboratory data on the $1^{\text {st }}$ and on the $10^{\text {th }}$ days.

2-D echocardiography was performed on days $1,3,7$ and 10 of inhospital stay. End-diastolic volume (EDV) and end-systolic volume (ESV), and left ventricle ejection fraction (LVEF) were assessed by Simpson method. EDV index (EDVI) and ESV index (ESVI) were calculated as a ratio of EDV and ESV to body surface area.

Renal function was estimated using creatinine level and its clearance $(\mathrm{CrCl})$ on admission and on the $10^{\text {th }}$ day using the Cockcroft-Gault formula.

\section{Endpoints and follow-up}

Short- and long-term prognosis was analyzed according to the following events: Cardiovascular (CV) deaths and non-fatal MI. Follow-up was conducted at 30 days and after 2 years. Information regarding adverse events was obtained from patients or their relatives during phone calls.

\section{Statistical methods}

Statistical analysis was assessed with "SPSS 11.0" software using Student's $t$-test, $\chi^{2}$-test, Wilcoxon non-parametric test, and Mann-Whitney test. Data were reported as means with $\mathrm{M} \pm \mathrm{m}$, the categorical variables were expressed as numbers with percentages. Survival rate was compared between groups using Kaplan-Meier plots and log-rank test. A value of $P<0.05$ was considered statistically significant.

\section{Results}

\section{Baseline characteristics}

A total of 1104 patients (54.1 \pm 0.4 years) were hospitalized due to STEMI between 2000 and 2010. AHF was diagnosed on the criteria - signs and symptoms of AHF Killip class II/III (pulmonary congestion presented during physical examination and/or confirmed on chest X-ray).

STEMI patients were divided into two groups: Patients with AHF symptoms on the $1^{\text {st }}$ day were classified as the $\mathrm{AHF}(+)$ group ( $n=340$ ) and those without heart failure - as the AHF(-) group $(n=764)$.

A total of $334 \mathrm{AHF}(+)$ patients were randomized into two groups according to the AHF duration: Transient AHFt(+) - with AHF occurred on the $1^{\text {st }}$ day and up to 3 days $(n=252)$ and persistent AHFp(+) - with AHF symptoms $>3$ days $(n=82)$ of inhospital period. Six patients were excluded from the study due to cardiogenic shock during in-hospital stay.

The mean time from the onset of AMI symptoms was $4.8 \pm$ $0.4 \mathrm{~h}$ and did not differ between groups. 
Patients with $\mathrm{AHFp}(+)$ were older $(P<0.05)$, presented mostly with anterior AMI $(P<0.01)$, lower $\operatorname{LVEF}(P<0.01)$ and higher heart rate $(P<0.05)$. They had significantly higher comorbidity rate such as previous history of angina pectoris $(P<0.05)$, hypertension $(P<0.05)$, chronic HF $(P<0.01)$, and diabetes $(P<0.01)$ compared to patients with $\operatorname{AHF}(-)$ and AHFt(+).

The shortest time from symptoms onset before thrombolysis ( $P$ $<0.05)$ was in the AHFp(+) group. The baseline characteristics of the patients are summarized in Table 1.

The patients received standard therapy according to the guidelines recommendations [Table 2].

It is generally accepted that the $3^{\text {rd }}$ day following $\mathrm{AMI}$ is a critical period because of LV early remodeling and systolic function impairment due to reperfusion injury, myocardial stunning

Table 1: Baseline characteristics of the studied patients - comparison of AMI patients groups with AHFt(+) and $A H F p(+)$ and group of patients with AMI without AHF - AHF(-)

\begin{tabular}{|c|c|c|c|}
\hline Variable & AHF(-) & AHFt(+) & AHFp(+) \\
\hline Patients, $\mathrm{n}$ & 764 & 252 & 82 \\
\hline Male sex, \% & 84.6 & 91.7 & 89.0 \\
\hline Age, years, $M \pm m$ & $53.1 \pm 0.4^{*}$ & $55.3 \pm 0.6$ & $59.3 \pm 1.0$ \\
\hline Smokers, \% & 55.4 & 58.3 & 50.0 \\
\hline $\mathrm{BMI}, \mathrm{kg} / \mathrm{m}^{2}, \mathrm{M} \pm \mathrm{m}$ & $27.0 \pm 0.2$ & $27.2 \pm 0.3$ & $27.9 \pm 0.4$ \\
\hline $\mathrm{BMI} \geq 30 \mathrm{~kg} / \mathrm{m}^{2}, \%$ & 22.1 & 20.2 & 25.6 \\
\hline \multicolumn{4}{|l|}{$\begin{array}{l}\text { Previous history } \\
\text { of }(\%)\end{array}$} \\
\hline Stable angina, \% & $36.8^{*}$ & 46.4 & 51.2 \\
\hline Unstable angina, \% & 38.5 & 41.7 & 41.5 \\
\hline MI, \% & 14.4 & 20.2 & 18.3 \\
\hline Chronic HF, \% & $16.1^{* *}$ & $15.5^{* *}$ & 31.7 \\
\hline Hypertension, \% & $45.4^{*}$ & $49.6^{*}$ & 60.9 \\
\hline Diabetes, \% & $7.8^{* *}$ & $6.0 * *$ & 18.3 \\
\hline $\begin{array}{l}\text { Time from onset } \\
\text { of AMI before } \\
\text { admission, hours }\end{array}$ & $4.8 \pm 0.2$ & $5.1 \pm 0.5$ & $4.3 \pm 0.4$ \\
\hline $\begin{array}{l}\text { Time from onset } \\
\text { of AMI before } \\
\text { thrombolysis, hours }\end{array}$ & $3.9 \pm 0.4^{*}$ & $3.5 \pm 0.2^{*}$ & $2.9 \pm 0.2$ \\
\hline Anterior AMI, \% & $49.4^{* *}$ & 62.7 & 74.4 \\
\hline LVEF, \% & $44.6 \pm 0.4^{* *}$ & $42.8 \pm 0.6^{* *}$ & $39.1 \pm 1.0$ \\
\hline $\mathrm{HR}, \mathrm{bpm}$ & $72.9 \pm 0.6^{*}$ & $75.0 \pm 1.3^{*}$ & $81.8 \pm 2.6$ \\
\hline $\mathrm{SBP}, \mathrm{mm} \mathrm{Hg}$ & $123.2 \pm 1.6$ & $121.1 \pm 2.4$ & $129.3 \pm 2.7$ \\
\hline $\mathrm{DBP}, \mathrm{mm} \mathrm{Hg}$ & $79.3 \pm 1.0$ & $76.8 \pm 1.9$ & $81.4 \pm 1.5$ \\
\hline
\end{tabular}

*Significant in compare with $\mathrm{AHFp}(+)$ group $P<0.05, * *$ Significant in compare with AHFp (+) group $P<0.01$, BMI: Body mass index, HR: Heart rate, SBP: Systolic blood pressure, DBP: Diastolic blood pressure, AMI: Acute myocardial infarction, AHF: Acute heart failure, LVEF: Left ventricle ejection fraction etc. Results of LV function showed significantly higher ESVI and lowered LVEF in the $\mathrm{AHFp}(+)$ group in comparison with those in $\mathrm{AHFt}(+)$ and $\mathrm{AHF}(-)$ patients on the $1^{\text {st }}$ and $3^{\text {rd }}$ day of in-hospital stay [Figure 1].

In our study, partial recovery of LV shape and contractile function occurred on the $7^{\text {th }}$ and $10^{\text {th }}$ days by EF increase and lower ESVI in AHF(-) and AHFt(+) patients in contrast to those in the $\mathrm{AHFp}(+)$ group.

Inflammation is a key pathogenic factor that plays an important role in the development of AHF. The analysis of the inflammation markers in peripheral blood during in-hospital period showed significantly higher CRP level on admission in $\mathrm{AHFp}(+)$ patients [Figure 2].

The severity and persistence of inflammation in patients with $\mathrm{AHFp}(+)$ was confirmed additionally by the increased ESR level on the $10^{\text {th }}$ day [Table 3].

Results of the studies involving AMI in experimental models have shown that VEGF promotes angiogenesis in infarct zone and reduces $\mathrm{MI}$ area. Marked increase in VEGF indicates a protective effect on patients as a result of angiogenesis and endothelial cell proliferation. According to its biological effects VEGF may improve the long-term prognosis of patients with

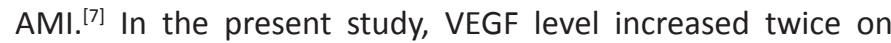
the $10^{\text {th }}$ day in AHF(-) and AHFt(+) patients. In the AHFp(+) group VEGF was high on admission but has been not risen up to the $10^{\text {th }}$ day of in-hospital period. To our opinion, this could be a marker of greater myocardial damage, inflammation, and worse survival.

Table 2: Treatment of patients with $\mathrm{AHFt}(+), \mathrm{AHFp}(+)$ and group of patients with AMI without AHF- AHF(-) during in-hospital course

\begin{tabular}{lccc}
$\begin{array}{l}\text { Type of treatment/ } \\
\text { medication }\end{array}$ & AHF(-) & AHFt(+) & AHFp(+) \\
\hline Thrombolysis, \% & $45.1^{*}$ & 54.4 & 51.3 \\
PCl, \% & 16.9 & 15.8 & 13.4 \\
UF Heparin, \% & 66.5 & 69.0 & 65.8 \\
LMW Heparin, \% & 35.2 & 44.8 & 36.6 \\
Acetylsalicylic acid, \% & 80.4 & 80.1 & 75.6 \\
Thienopyridines, \% & 17.8 & 16.3 & 15.9 \\
Beta-blockers, \% & 96.2 & 96.0 & 97.6 \\
ACEl, \% & $60.2^{* *}$ & 77.0 & 82.9 \\
ARB, \% & $8.1^{*}$ & 12.7 & 11.1 \\
Diuretics, i.v., \% & $11.1^{* *}$ & $24.6^{* *}$ & 67.1 \\
Aldosteroneblockers,\% & $5.5^{* *}$ & $14.7^{*}$ & 25.6 \\
\hline
\end{tabular}

*Significant in compare with $\mathrm{AHFp}(+)$ group $P<0.05, * *$ significant in compare with $\mathrm{AHFp}(+)$ group $P<0.001$, ACEI: Angiotensin enzyme converting inhibitor, ARB: Angiotensin receptors blocker, LMW Heparin - low molecular weight heparin, $\mathrm{PCl}$ : Percutaneous intervention, AMI: Acute myocardial infarction, AHF: Acute heart failure 

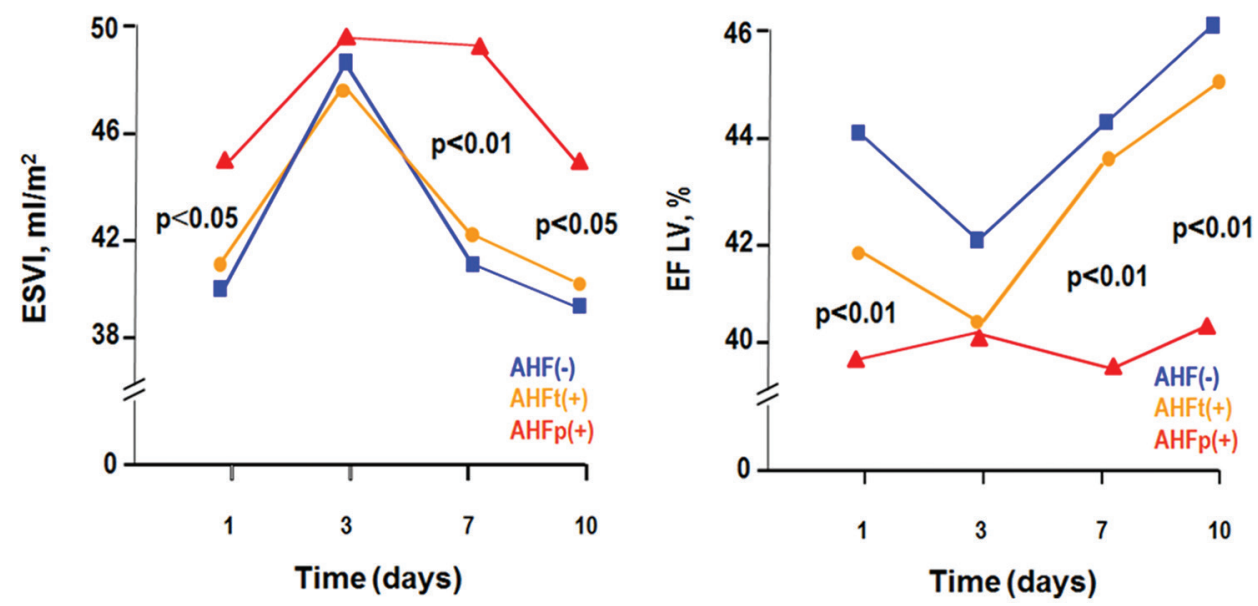

Figure 1: Changes of end-systolic volume index and left ventricle ejection fraction in acute myocardial infarction patients

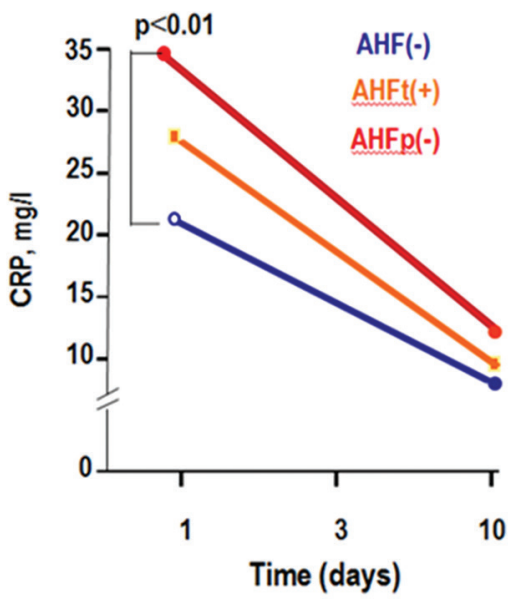

Figure 2: C-reactive protein levels in acute myocardial infarction patients

AHFt(+) and $\mathrm{AHFp}(+)$ patients have significantly greater infarct size according to the levels of serial MB-CK in compare to those in $\mathrm{AHF}(-)$ patients [Figure 3].

Both $\mathrm{AHFt}(+)$ and $\mathrm{AHFp}(+)$ patients demonstrated increased glucose level on admission [Figure 4].

In AMI normal hormonal control of blood glucose concentration is disturbed by the stress. Irrespective of diabetes status is quite common for blood glucose to be raised in the immediate period following $\mathrm{AMI}{ }^{[8]}$

Several reports have evaluated an association between hyperglycemia and mortality following MI. ${ }^{[8]}$

Renal impairment on admission in patients presented with AHF is common sign, occurred approximately in half of the patients and associated with high mortality. ${ }^{[9]}$
In our study $\mathrm{CrCl}$ rate was significantly lower on admission in patients with $\mathrm{AHFp}(+)$ in compare to both $\operatorname{AHF}(-)(P<0.05)$ and $\mathrm{AHFt}(+)$ patients $(P<0.05)$. On the $10^{\text {th }}$ day, $\mathrm{CrCl}$ level was decreased in all groups of patients, but significantly lower it was only in $\mathrm{AHFp}(+)$ group [Figure 5].

\section{Hospital and post-discharge outcomes}

Patients from both $\mathrm{AHFt}(+)$ and $\mathrm{AHFp}(+)$ groups had higher in-hospital complications rate than patients without AHF(-). Detailed analysis is presented in Table 4.

During the following 30 days $\mathrm{AHFp}(+)$ patients had higher incidence rate of $\mathrm{CV}$ death and non-fatal $\mathrm{MI}$ in compare with those in $\mathrm{AHF}(-)$ (7.3 \% vs $1.2 \%, \mathrm{P}<0.01$ and $12.2 \%$ vs $5.8 \%$, $\mathrm{P}<0.01)$ and $\mathrm{AHFt}(+)(7.3 \%$ vs $2.1 \%, \mathrm{P}<0.05$ and 12.2 vs $3.2 \%$, $P<0.01)$ groups.

CV mortality and non-fatal $\mathrm{MI}$ were significantly higher in the $\mathrm{AHFp}(+)$ group as compared to $\mathrm{AHFt}(+)$ and $\mathrm{AHF}(-)$ group during long-term follow-up [Figure 6].

\section{DISCUSSION}

AHF is a complex clinical syndrome characterized by the rapid symptom occurrence due to LV contractile function failure: Inadequate tissue perfusion, high lung capillary pressure, and tissue congestion. Patients with AMI complicated by AHF have worse short- and long-term survival rate. ${ }^{[10,11]}$

According to the US National Registry of Myocardial Infarction data AHF occurrence in AMI patients was more than $20 \%$ on admission and additionally in 9\% during in-hospital stay. ${ }^{[12]}$ In the French study, AHF was presented in 38\% patients during 5 days after AMI onset. AHF symptoms developed mostly within the first $24 \mathrm{~h}$ of $\mathrm{AMI}$ with next worsening on the $4^{\text {th }}$ day. ${ }^{[13]}$ In our study, signs and symptoms of AHF in AMI patients were 
Table 3: Comparison of biochemical parameters in patients with $\mathrm{AHFt}(+), \mathrm{AHFp}(+)$ and group of patients with AMI without AHF - AHF(-)

\begin{tabular}{|c|c|c|c|}
\hline Variable & AHF(-) & AHFt(+) & AHFp(+) \\
\hline Hemoglobin, $g / l$ (on $1^{\text {st }}$ day) & $138.3 \pm 0.5$ & $139.2 \pm 0.8$ & $137.7 \pm 1.5$ \\
\hline Hemoglobin, $\mathrm{g} / \mathrm{l}$ (on $10^{\text {th }}$ day) & $131.6 \pm 0.7$ & $131.5 \pm 1.0$ & $128.9 \pm 1.9$ \\
\hline Platelets, $\times 10^{9} /$ ( on $1^{\text {st }}$ day) & $233.5 \pm 7.0$ & $230.8 \pm 9.7$ & $238.0 \pm 17.0$ \\
\hline Platelets, $\times 10^{9} /$ ( on $10^{\text {th }}$ day) & $255.0 \pm 7.4$ & $247.4 \pm 9.3$ & $224.5 \pm 12.5$ \\
\hline VGEF, pg/ml (on $1^{\text {st }}$ day) & $95.3 \pm 17.8^{* *}$ & $123.3 \pm 37.6^{*}$ & $391.2 \pm 147.5$ \\
\hline VGEF, pg/ml (on $10^{\text {th }}$ day) & $209.6 \pm 28.8$ & $223.4 \pm 44.9$ & $428.1 \pm 99.0$ \\
\hline $\mathrm{ESR}, \mathrm{mm} / \mathrm{h}$ (on $1^{\text {st }}$ day) & $8.5 \pm 0.4$ & $8.5 \pm 0.5$ & $9.0 \pm 0.9$ \\
\hline ESR, mm/h (on $10^{\text {th }}$ day) & $16.9 \pm 0.8$ & $17.2 \pm 1.1^{*}$ & $22.0 \pm 1.9$ \\
\hline WBC, $\times 10^{9} /$ ( on $1^{\text {st }}$ day) & $9.2 \pm 0.1$ & $9.4 \pm 0.2$ & $9.8 \pm 0.4$ \\
\hline WBC, $\times 10^{9} /$ I (on $10^{\text {th }}$ day) & $8.5 \pm 0.2$ & $7.8 \pm 0.2$ & $8.4 \pm 0.3$ \\
\hline CRP, mg/l, (on $1^{\text {st }}$ day) & $22.1 \pm 1.4^{* *}$ & $26.9 \pm 2.3$ & $35.6 \pm 3.9$ \\
\hline CRP, $\mathrm{mg} / \mathrm{l}$, (on $10^{\text {th }}$ day) & $10.7 \pm 0.8$ & $11.1 \pm 1.0$ & $13.3 \pm 2.5$ \\
\hline
\end{tabular}

*Significant in compare with AHFp(+) group $P<0.05,{ }^{* *}$ significant in compare with AHFp(+) group $P<0.01$, CRP: C-reactive protein, WBC: White blood cells, ESR: Erythrocyte sedimentation rate, VGEF: Vascular endothelial growth factor, AMI: Acute myocardial infarction, AHF: Acute heart failure

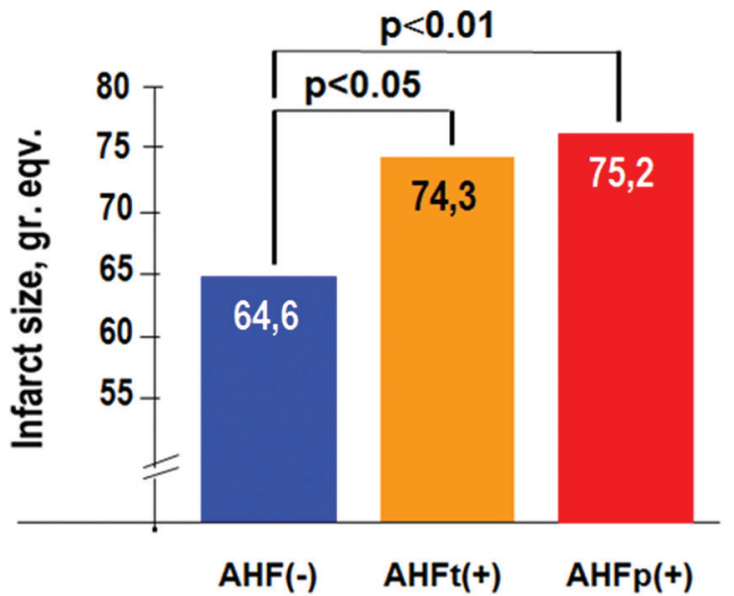

Figure 3: Infarct size by serial measurement of $\mathrm{MB}-\mathrm{CK}$ in acute myocardial infarction patients Both AHFt(+) and $A H F p(+)$ patients demonstrated increased glucose level on admission [Figure 4]

presented in $30.8 \%$ on the $1^{\text {st }}$ day and in $9 \%$ - occurred during in-hospital stay.

AHF in AMI patients has been associated with an increase of in-hospital mortality from $6 \%$ (with preserved EF) up to $80 \%$ (with cardiogenic shock) during the $1^{\text {st }}$ year following AMI - it can reach $30 \%$. In agreement with modern concepts, systolic LV dysfunction is a predictive factor of adverse outcomes. ${ }^{[14]}$

Reperfusion therapy is very important because both systemic TLT and percutaneous coronary interventions limit myocardial damage. Infarct size is the key determinant for stratification patients after MI. In our study, myocardial revascularization was

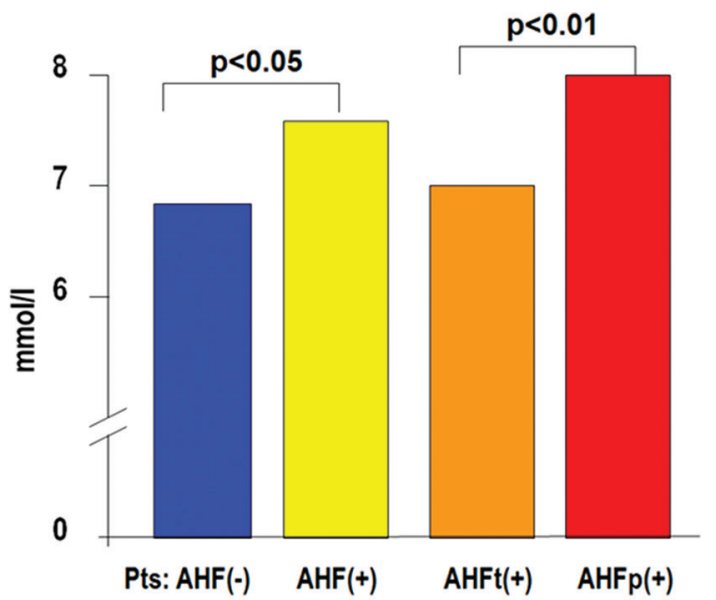

Figure 4: Levels of glucose on admission in acute myocardial infarction patients

performed in $64 \%$ patients, and infarct size was significantly higher in ST-elevation AMI patients with AHF. ${ }^{[15]}$

$\mathrm{AHF}$ as an $\mathrm{AMI}$ complication is a result of complex interaction of structural, hemodynamic, neurohumoral and genetic changes. Sudden myocytes loss leads to contractile dysfunction resulting in AHF manifestation where the level of myocardial damage biomarkers closely correlates with the degree of LV function recovery and prognosis. ${ }^{[16]}$

Myocardial infarction size and postischemic LV systolic dysfunction that lead to AHF, can be the result of myocardial necrosis, stunning and/or hibernation, which in turn depend on coronary perfusion. ${ }^{[17]}$ In our study, AHFt(+) and AHFp(+) patients had significantly greater infarct size according to the levels of serial MB-CK in compare to those in AHF(-) patients. 
Table 4: Comparison of in-hospital complications in patients with AHFt(+), AHFp(+) and group of patients with AMI without AHF - AHF(-)

\begin{tabular}{lccc} 
Variable & AHF(-) & AHFt(+) & AHFp(+) \\
Recurrent angina, \% & $5.9^{*}$ & 8.3 & 14.6 \\
Reinfarction, \% & $5.8^{*}$ & $3.2^{* *}$ & 12.2 \\
LV aneurism, \% & $8.5^{* * *}$ & $15.9^{* *}$ & 25.7 \\
Ventricular fibrillation/tachycardia, \% & 4.8 & 4.2 & 4.8 \\
A-V block, \% & $3.1^{*}$ & 3.2 & 8.5 \\
Bundle branch block, \% & - & $5.2^{* *}$ & 19.5 \\
Atrial fibrillation, \% & $2.2^{* *}$ & $2.0^{* *}$ & 19.5 \\
Cardiogenic shock, \% & - & $0.6^{*}$ & 4.9 \\
\hline
\end{tabular}

*Significant in compare with $\mathrm{AHFp(+)}$ group $P<0.05, * *$ significant in compare with AHFp(+) group $P<0.01,{ }^{* * *}$ significant in compare with AHFp(+) group $P<0.001$, AMI: Acute myocardial infarction, AHF: Acute heart failure

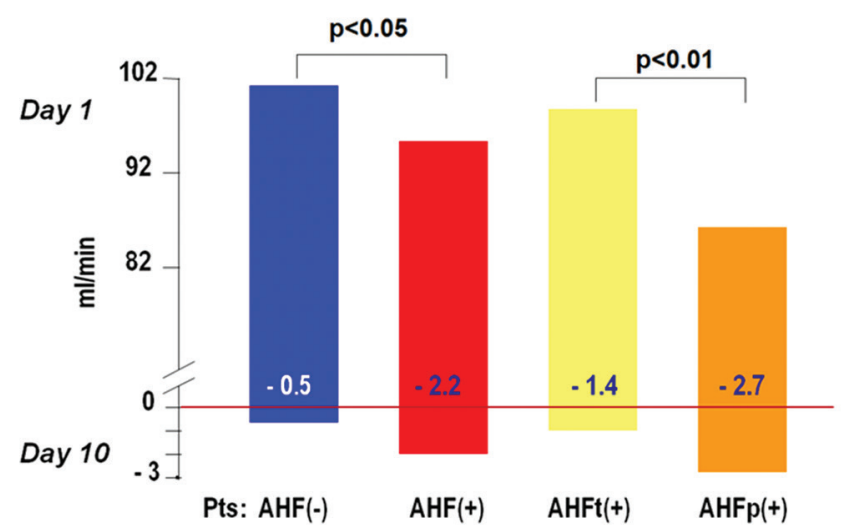

Figure 5: Changes of $\mathrm{CrCl}$ on the $1^{\text {st }}$ and $10^{\text {th }}$ days in acute myocardial infarction patients

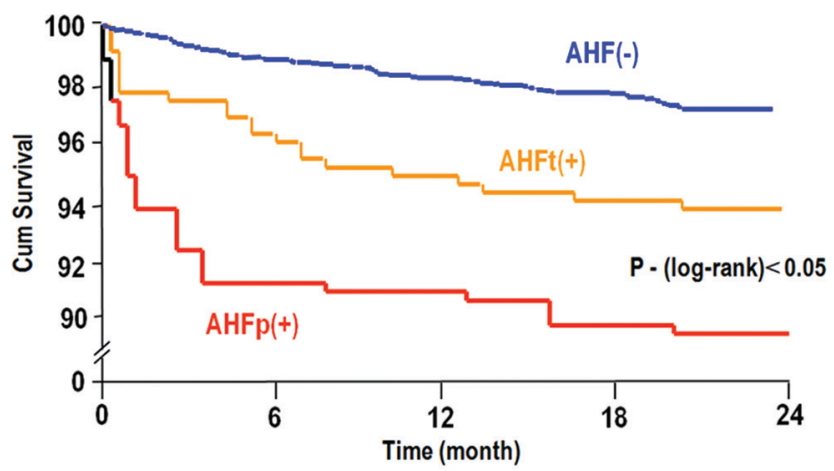

Figure 6: Kaplan-Meier survival analysis in acute myocardial infarction patients

Heart remodeling includes genes expression, molecular, cellular and interstitial alterations that are characterized by changes of ventricular size, shape and function after myocardial injury. Pathological LV remodeling occurs in AMI patients with greater regional contractility disorders that are also mediated by coronary perfusion. Abnormal myocardium relaxation due to ischemia cause impairment of LV filling and its global systolic function and as a consequence - lead to AHF. In addition, ischemia may be the cause acute mitral regurgitation, and thus to promote pulmonary congestion. ${ }^{[18]}$

The remodeling process mainly depends on the hemodynamic load, neurohormonal and inflammation activation. It has been proven that the process of LV remodeling begins during the $1^{\text {st }}$ hours of AMI (expansion of the infarct zone) and may continue for a long time (time-dependent dilatation, the distortion of ventricular shape), which results in EDVI and ESVI increasing with LVEF decline. ${ }^{[19]}$ Our findings showed features of pathological remodeling in $\mathrm{AHFp}(+)$ by the higher meanings of ESVI and lower LVEF on the $1^{\text {st }}$ and $3^{\text {rd }}$ day of $A M I$ in compare with those in $\mathrm{AHFt}(+)$ and $\mathrm{AHF}(-)$ patients.

Inflammation markers could reflect the myocardium healing. In our study high CRP level on admission was in STEMI patients with $\mathrm{AHF}(+)$, especially in $\mathrm{AHFp}(+)$ patients $(\mathrm{P}<0.01)$ comparatively to $A H F(-)$ group. Results of clinical trials underline that high CRP level has been associated with higher mortality rate in patients with AMI. ${ }^{[20]}$

Patients with AMI have elevated circulating VEGF levels in comparison with healthy subjects. VEGF enhances vascular permeability, accelerates collateral formation in ischemic myocardium and promotes tissue repair after wound healing. ${ }^{[7]}$

In our study, VEGF level increased twice on the $10^{\text {th }}$ day in AHF(-) and $\mathrm{AHFt}(+)$ patients, whereas in the AHFp(+) group VEGF was high on admission, but did not increase up to the $10^{\text {th }}$ day of in-hospital period. To our opinion, this could be a marker of greater myocardial damage, inflammation and worse survival.

Despite of a strong evidence linking decreased glomerular filtration rate to worse outcomes, the impact of $\mathrm{CrCl}$ on mortality and morbidity in patients with $\mathrm{AMI}$ and $\mathrm{AHF}$ is not well defined. ${ }^{[21]}$ According to our results, $\mathrm{CrCl}$ level was associated with severity and duration of AHF symptoms that connected with higher rate of complications and poor survival.

Therefore, according to guidelines LV systolic function should be routinely assessed by echocardiography in all AMI patients on the $10^{\text {th }}$ day for individualized management depending on the LV EF. In our opinion, it is necessary to use more aggressive therapy to improve the prognosis of AMI patients with AHF. This category includes elderly patients, those with diabetes mellitus, history of coronary artery disease, anterior MI, and newly emerged bundle branch blocks.

Optimal medical therapy in patients with AHF based on guidelines should include beta-blockers, ACE inhibitors or angiotensin II receptor blockers and aldosterone receptor

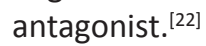


However, according to real clinical practice, patients with AHF are less likely to receive aspirin, heparin, beta-blockers and reperfusion therapy. ${ }^{[12]}$

In our study we demonstrated dependence on the outcomes on the time of onset of AHF and its duration. AMI patients with $\mathrm{AHFp}(+)$ during in-hospital stay presented more frequent complications such as recurrent $\mathrm{MI}$ and angina, LV aneurysm, and ventricular arrhythmias.

AHFp(+) patients had also renal dysfunction (RD) on admission. $\mathrm{RD}$ is an independent risk factor of adverse outcomes both in AMI and AHF patients despite of age, gender and glucose intolerance degree. ${ }^{[9]}$ At the same time, RD leads to fluid retention, activation of the renin-angiotensin system, increasing of proinflammatory cytokines and endothelial dysfunction. Reduced glomerular filtration rate $\left(<60 \mathrm{ml} / \mathrm{min} / 1.73 \mathrm{~m}^{2}\right)$ is not associated with the level of cardiac markers, infarct size, or ST segment elevation but is strongly related to CV history and initial LV function. ${ }^{[23]}$

In our study, $\mathrm{AHF}(+)$ was associated with increase of 30 days and 2 years mortality rates in compare with those observed in patients without AHF(-). Particularly, AMI patients with persistent $\mathrm{AHF}(+)$ had significantly higher complications rate during in-hospital period and long-term outcome.

\section{Study limitations}

Certain limitations must be considered during interpreting our study. First, this study represents patients with AHF in the presence of AMI only from one center. Second, in presented study, AMI patients had low percent of $\mathrm{PCl}$ performing. Further studies are required to confirm our findings on larger populations of patients with AHF terms in the setting of AMI. Incidence of high mortality rate in patients with $\mathrm{AHF}$ requires both more aggressive treatment on admission and effective AHF prevention.

\section{Conclusion}

Our study shows that AHF is a frequent complication of STsegment elevation AMI. The AHF incidence in the first $24 \mathrm{~h}$ after admission and during in-hospital stay is similar to data reported in previous studies.

AHF on admission and up to 3 days has not important impact on MACE incidence in AMI patients.

STEMI patients with AHF lasting $>3$ days have worse short- and long-term prognosis. Therefore, an aggressive strategy should be recommended, particularly in patients who have clinical signs and symptoms of persistent AHF.

\section{References}

1. McManus DD, Chinali M, Saczynski JS, Gore JM, Yarzebski J, Spencer FA, et al. 30-year trends in heart failure in patients hospitalized with acute myocardial infarction. Am J Cardiol 2011;107:353-9.

2. Chen J, Hsieh AF, Dharmarajan K, Masoudi FA, Krumholz HM. National trends in heart failure hospitalization after acute myocardial infarction for medicare beneficiaries: 19982010. Circulation 2013;128:2577-84.

3. Butler J, Kalogeropoulos A. Worsening heart failure hospitalization epidemic we do not know how to prevent and we do not know how to treat! J Am Coll Cardiol 2008;52:435-7.

4. Araszkiewicz A, Grygier M, Lesiak M, Grajek S. The impact of ischemia-reperfusion injury on the effectiveness of primary angioplasty in ST-segment elevation myocardial infarction. Postepy Kardiol Interwencyjnej 2013;9:275-81.

5. Eltzschig HK, Eckle T. Ischemia and reperfusion-from mechanism to translation. Nat Med 2011;17:1391-401.

6. Littnerova S, Kala P, Jarkovsky J, Kubkova L, Prymusova K, Kubena $\mathrm{P}$, et al. GRACE score among six risk scoring systems (CADILLAC, PAMI, TIMI, dynamic TIMI, zwolle) demonstrated the best predictive value for prediction of long-term mortality in patients with ST-elevation myocardial infarction. PLoS One 2015;10:e0123215.

7. Niu J, Han X, Qi H, Yin J, Zhang Z, Zhang Z, et al. Correlation between vascular endothelial growth factor and long-term prognosis in patients with acute myocardial infarction. Exp Ther Med 2016;12:475-9.

8. Zhao S, Murugiah K, Li N, Li X, Xu ZH, Li J, et al. Admission glucose and inhospital mortality after acute myocardial infarction in patients with or without diabetes: A Crosssectional study. Chin Med J 2017;130:767-75.

9. Amin AP, Spertus JA, Reid KJ, Lan X, Buchanan DM, Decker $C$, et al. The prognostic importance of worsening renal function during an acute myocardial infarction on long-term mortality. Am Heart J 2010;160:1065-71.

10. Krzysztofik JM, Sokolski M, Kosowski M, Zimoch W, Lis A, Klepuszewski $\mathrm{M}$, et al. Acute heart failure in patients admitted to the emergency department with acute myocardial infarction. Kardiol Pol 2017;75:306-15.

11. Ural D, Çavuşoğlu $Y$, Eren $M$, Karaüzüm $K$, Temizhan $A$, Birhan $M$, et al. Diagnosis and management of acute heart failure. Anatol J Cardiol 2016;15:860-89.

12. Spencer FA, MeyerTE, Gore JM, Goldberg RJ. Heterogeneity in the management and outcomes of patients with acute myocardial infarction complicated by heart failure: The national registry of myocardial infarction. Circulation 2002;105:2605-10.

13. Zannad $F$, Mebazaa A, Juillière $Y$, Cohen-Solal A, Guize $L$, Alla $\mathrm{F}$, et al. Clinical profile, contemporary management and one-year mortality in patients with severe acute heart failure syndromes: The EFICA study. Eur J Heart Fail 2006;8:697-705.

14. Parissis JT, Ikonomidis I, Rafouli-Stergiou P, Mebazaa A, Delgado J, Farmakis D, et al. Clinical characteristics and predictors of in-hospital mortality in acute heart failure with preserved left ventricular ejection fraction. Am J Cardiol 2011;107:79-84. 
15. Cahill TJ, Kharbanda RK. Heart failure after myocardial infarction in the era of primary percutaneous coronary intervention: Mechanisms, incidence and identification of patients at risk. World J Cardiol 2017;9:407-15.

16. French BA, Kramer CM. Mechanisms of post-infarct left ventricular remodeling. Drug Discov Today Dis Mech 2007;4:185-96.

17. Minicucci MF, Farah E, Fusco DR, Cogni AL, Azevedo PS, Okoshi $\mathrm{K}$, et al. Infarct size as predictor of systolic functional recovery after myocardial infarction. Arq Bras Cardiol 2014;102:549-56.

18. Carrick D, Haig C, Rauhalammi S, Ahmed N, Mordi I, McEntegart $M$, et al. Pathophysiology of LV remodeling in Survivors of STEMI: Inflammation, remote myocardium, and prognosis. JACC Cardiovasc Imaging 2015;8:779-89.

19. Konstam MA, Kramer DG, Patel AR, Maron MS, Udelson JE. Left ventricular remodeling in heart failure: Current concepts in clinical significance and assessment. JACC
Cardiovasc Imaging 2011;4:98-108.

20. Sharif D, Hammoud M, Sharif-Rasslan A, Abinader E, Odeh M. Very early C-reactive protein levels after acute myocardial infarction predict early outcome and late prognosis. Int J Clin Med 2015;6:547-53.

21. Almeida I, Caetano F, Barra S, Madeira M, Mota P, LeitãoMarques $A$, et al. Estimating glomerular filtration rate in acute coronary syndromes: Different equations, different mortality risk prediction. Eur Heart J Acute Cardiovasc Care 2016;5:223-30.

22. Teichman SL, Maisel AS, Storrow AB. Challenges in acute heart failure clinical management: Optimizing care despite incomplete evidence and imperfect drugs. Crit Pathways Cardiol 2015;14:12-24.

23. Amin AP, Salisbury AC, McCullough PA, Gosch K, Spertus JA, Venkitachalam L, et al. Trends in the incidence of acute kidney injury in patients hospitalized with acute myocardial infarction. Arch Intern Med 2012;172:246-53. 